CASE REPORT

\title{
Tonsillar Actinomycosis with Multiple Epidermoid Cysts: A Rare Case Report
}

\author{
Urvashi Mishra ${ }^{1}$, Vijay Giridher ${ }^{2}$, Zaid Ahmad Ansari ${ }^{3}$
}

\begin{abstract}
Aim and objective: To report a case of multiple epidermoid cysts of the tonsil with actinomycosis in a 56-year-old female patient who presented with discomfort in the throat.

Background: The Actinomyces spp. are common saprophytic microorganisms, which are found in the oral cavity, pharynx, and palatine tonsils. The actinomycotic infections can be responsible for recurrent chronic tonsillitis. Epidermoid cysts are benign lesions that can be encountered anywhere in the body, usually seen in neck, chest, or trunk.

Case description: This study reports a case of multiple epidermoid cysts of the tonsil with actinomycosis in a 56-year-old female patient presented to our ENT outpatient department with discomfort in the throat and presence of a few whitish masses over her right tonsil, which was her major concern. She underwent a tonsillectomy followed by a course of antibiotic for 3 weeks; the diagnosis was confirmed by histology. Conclusion: Though tonsillitis is the commonest lesion diagnosed in all age groups, histopathology plays an important role in diagnosis of various other non-neoplastic and neoplastic lesions of tonsil. There might be existence of two separate clinical entities in a single case, one being the causative factor of another.

Clinical significance: Our results indicate that actinomycetes may play an active role in the etiology of the epidermoid cyst of the tonsillar tissue. The clinical importance of recognizing this organism lies in the fact that definitive treatment requires a long course of penicillin group antibiotics even after surgical excision. To the best of our knowledge, this is the first case report in the English-indexed literature.
\end{abstract}

Keywords: Actinomyces, Epidermoid cyst, Multiple cysts, Palatine tonsil.

Otorhinolaryngology Clinics: An International Journal (2019): 10.5005/jp-journals-10003-1335

\section{INTRODUCTION}

The palatine tonsil is a mass of lymphoid tissue situated in the lateral wall of the oropharynx, where it lies within the tonsillar fossa. It plays an extremely remarkable role in the antimicrobial defense of the body. Actinomycosis are filamentous branched bacteria, living as commensal organisms in the oral cavity, becoming invasive when, through a mucosal lesion, they gain access to the subcutaneous tissue. Actinomycosis can present in a variety of forms and may mimic other infections or even neoplasm. The clinical significance of presence of Actinomyces in tonsils and its role in pathogenesis of tonsillitis is a topic of debate for long. ${ }^{1}$ A varieties of cysts can arise in the tonsil with tonsillar retention cyst being the most common. Epidermoid cyst, lymphoepithelial cyst, and hydatid cyst are other rare causes of tonsillar cyst. ${ }^{2}$ Intraoral epidermoid cysts involve $0.01 \%$ of the population. ${ }^{3}$ The incidence of epidermoid cysts in the head and neck has been found to be $1.6-6.9 \% .{ }^{4}$ Various studies have been postulated in its pathogenesis, which include the inclusion of ectodermal tissues during embryogenesis and metaplasia in response to prolonged irritation. ${ }^{5}$

\section{Case Description}

A 56-year-old woman presented to our ENT outpatient department with discomfort in the throat for 6 months. She incidentally noticed few whitish masses over her right tonsil, which was her major concern. There was no dysphagia or dyspnea. On examination, she had enlargement of her right tonsil with multiple whitish cysts over the tonsillar surface. The right tonsil was larger in size than the left (Fig. 1). There was no cervical lymphadenopathy. Blood and urine examination was within normal limit. The patient was
${ }^{1-3}$ Department of Otorhinolaryngology, Jaipur Golden Hospital, New Delhi, India

Corresponding Author: Urvashi Mishra, Department of Otorhinolaryngology, Jaipur Golden Hospital, New Delhi, India, Phone: +919560705357, e-mail:dr.urvashi15@gmail.com

How to cite this article: Mishra U, Giridher V, Ansari ZA. Tonsillar Actinomycosis with Multiple Epidermoid Cysts: A Rare Case Report. Int J Otorhinolaryngol Clin 2019;11(3):76-78.

Source of support: Nil

Conflict of interest: None

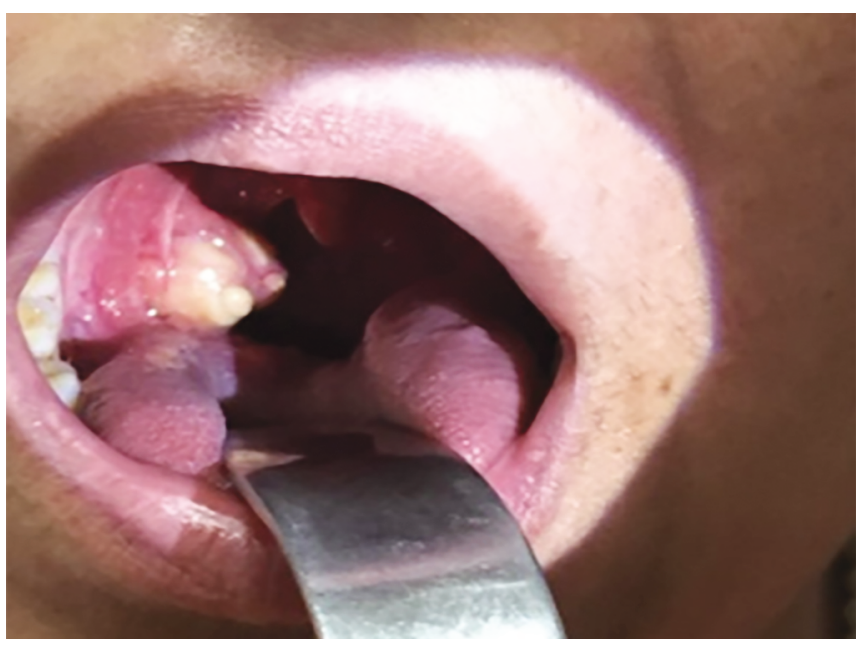

Fig. 1: View of the asymmetrical hypertrophy of the right tonsil with multiple cysts 


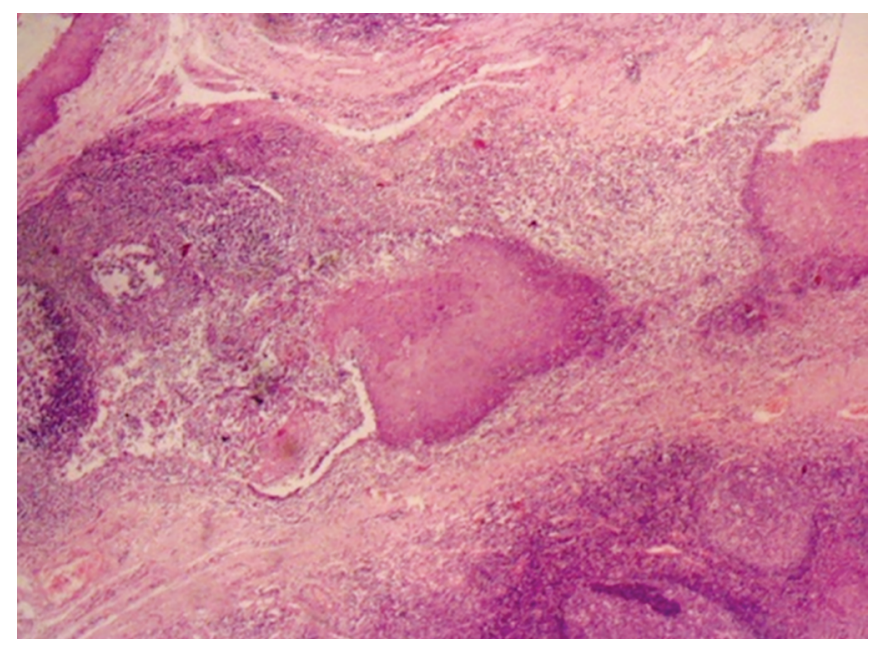

Fig. 2: Cystic cavity within the tonsillar tissue lined with keratinized epithelium (H/E 40X)

assessed for the HIV status and was found seronegative. We planned tonsillectomy as asymmetrical adult tonsils with normal mucosa in the absence of cervical lymphadenopathy are associated with $7 \%$ risk of malignancy. ${ }^{6}$ Under general anesthesia, bilateral coblation tonsillectomy was done. The procedure was uneventful. The specimen was sent for histopathology. The patient was discharged on the 2nd postoperative day. Follow-up was uneventful. Histologic evaluation of the specimens was done on the hematoxylin- and eosin-stained slide that showed tonsil with a cyst lined by stratified squamous epithelium showing ulceration with formation of the keratinous cyst. There are colonies of Actinomyces among the hyperplastic lymphoid follicle along with dense acute inflammation (Figs 2 and 3). A diagnosis of tonsillar actinomycosis with infected epidermoid cyst of the tonsil was made. The uneventful healing of the fossa was noted by 1 week. The patient was started on a combination of amoxicillin (500 mg) with clavulanic acid (125 mg) for 3 weeks. ${ }^{7}$ The patient made complete recovery and, moreover, follow-up revealed no recurrence of the infection and/or cyst.

\section{Discussion}

Chronic tonsillitis most often affects children, but can be seen in adults. Many studies have stated that chronic inflammation is present in both tonsillitis and tonsillar hypertrophy. The differential diagnosis to be considered for tonsillar hypertrophy includes tonsillar tumors, tumors of parapharyngeal space, infectious etiology, and inclusion cysts. Cervicofacial involvement is the most common manifestation of actinomycosis, accounting for $50 \%$ of all cases. ${ }^{8}$ The pathogenesis is related to its ability to act as an intracellular parasite and thus resist phagocytosis as well as its tendency to spread without respect for established tissue plains or anatomic barriers. Actinomyces are gram-positive, nonacid fast, anaerobic or microaerophilic filamentous branched bacteria that are very difficult to grow in culture, with $<30 \%$ of cultures being positive. These bacteria are all normal commensals of the human oral cavity. For the diagnosis of actinomycosis to be established, typical findings on histological examination of the tissue with an outer zone of granulation tissue and a central zone of necrosis containing many granules that represent microcolonies of Actinomyces should be present. ${ }^{9}$ Van Lierop et al. found no tissue reaction due to Actinomyces colonies and hence reported no correlation between

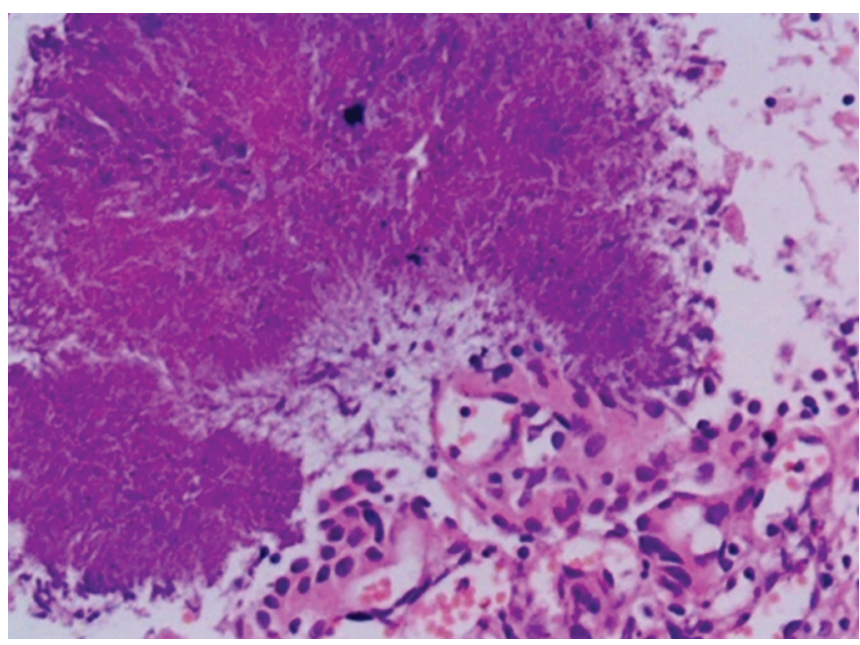

Fig. 3: High power view showing Actinomyces colony with "sunray appearance" (H/E, 100X)

tonsillar actinomycosis and recurrent tonsillitis. ${ }^{10}$ Contrary to this, Aydin et al. analyzed 1,820 tonsillectomy specimens and reported that cryptitis was a common histopathologic indicator of tonsillar actinomycosis. $^{11}$

Histologically, there are three types of dermoid cysts, i.e., epidermoid cyst, true dermoid cyst, and teratoid. Roser, in 1859, described the term "epidermoid cyst." Epidermoid is a type of dermoid cyst, commonly seen in face, neck, chest, or trunk-usually occurs just beneath the skin. ${ }^{12}$ The occurrence of epidermoid cysts in the mouth is extremely rare. These cysts generally present slow and progressive growth, and even if they are congenital, they often are not diagnosed until the second or third decade of life.

Basal cell carcinoma and squamous cell carcinoma arising in the wall of an otherwise conventional epidermoid cyst have been seen. ${ }^{13-15}$ However, no carcinomatous transformation was noted in our case.

\section{Conclusion}

Though tonsillitis is the commonest lesion diagnosed in all age groups, histopathology plays an important role in diagnosis of various other non-neoplastic and neoplastic lesions of the tonsil. The histopathological examination of tonsils in our case report also documents Actinomyces colonies with infected epidermoid cyst. Dense acute inflammation caused by actinomycosis might be a reason for development of epidermoid cysts in a rare site like tonsils. In conclusion, epidermoid cysts as well as actinomycosis, a rare occurrence in the head and neck area, can also be found inside the palatine tonsils and cause asymmetrical hypertrophy. The clinical importance of recognizing this organism lies in the fact that definitive treatment requires a long course of penicillin group antibiotics even after surgical excision. ${ }^{7}$ There might be existence of two separate clinical entities in a single case, one being the causative factor of another. There has been evidence of carcinomatous transformations in epidermoid cysts; hence, the patient should be kept in regular follow-up.

\section{Clinical Significance}

We herewith report a case of exceptional existence of multiple epidermoid cysts of the tonsil with actinomycosis. To the best of 
our knowledge, it is the first report in the English-indexed literature. This study also emphasizes on the need for further research into the etiopathogenesis of the cysts and the sequels of actinomycosis infections.

\section{References}

1. Priyadarshini SA, Shubhashree AR, Ganapathy H. Actinomycosis of tonsils-incidental or pathological? - A case report. Int J Pharm Bio Sci 2014;5(4):164-168.

2. Shobha K, Kumar H, Raj D, et al. Epidermoid cyst in tonsil: a rare presentation. Transw Med J 2014;2(1):75-76.

3. Kini YK, Kharkar VR, Rudagi BM, et al. An unusual occurrence of epidermoid cyst in the buccal mucosa: a case report with review of literature. J Maxillofac Oral Surg 2013;12(1):90-93. DOI: 10.1007/ s12663-011-0188-y.

4. Shivakumar MS, Yogesh TL, Nagaraj T, et al. Epidermal inclusion cyst of buccal mucosa: a rare case report. Int J Med Dent Case Rep 2015. 050115.

5. Gulia SP, Lavanya M, Kamidi V, et al. Epidermoid cyst of the tonsil: an incidental finding. Int J Adv Case Rep 2015;2:777-779.

6. Macnamara M. Acute and chronic pharyngeal infections. In: Gleeson M, ed. Scott-Brown's Otorhinolaryngology. 7th ed., Hodder Arnold; 2008. pp. 1981-2025.

7. Dejan R, Aleksandar P, Biserka VD. A case of an unilateral tonsillar hypertrophy caused by actinomycosis. Acta Medica (Hradec Králové) 2010;53(1):31-33.
8. Kwartler JA, Limaye A. Pathologic quiz case 1. Cervicofacial actinomycosis. Arch Otolaryngol Head Neck Surg 1989;115(4):524527. DOI: 10.1001/archotol.1989.01860280122032.

9. Mohanty S. Actinomycosis of faucial tonsil masquerading as oropharyngeal malignancy. Indian J Otolaryngol Head Neck Surg 2006;58(1):82-84.

10. van Lierop AC, Prescott CA, Sinclair-Smith CC. An investigation of the significance of actinomycosis in tonsil disease. Int $J$ Pediatr Otorhinolaryngol 2007;71(12):1883-1888. DOI: 10.1016/j. ijporl.2007.08.021.

11. Aydin A, Erkiliç S, Bayazit YA, et al. Relation between actinomycosis and histopathological and clinical features of the palatine tonsils: a comparative study between adult and pediatric patients. Rev Laryngol Otol Rhinol (Bord) 2005;126(2):95-98.

12. Mammen S, Korulla A, Paul MJ. An epidermal cyst in the floor of the mouth: a rare presentation. J Clin Diagn Res 2013;7(2):381-382. DOI: 10.7860/JCDR/2013/4165.2776.

13. Ikeda I, Ono T. Basal cell carcinoma originating from an epidermoid cyst. J Dermatol 1990;17(10):643-646. DOI: 10.1111/j.1346-8138.1990. tb01709.x.

14. López-Ríos F, Rodríguez-Peralto JL, Castaño E, et al. Squamous cell carcinoma arising in a cutaneous epidermal cyst: case report and literature review. Am J Dermatopathol 1999;21(2):174-177. DOI: 10.1097/00000372-199904000-00012.

15. Devine JC, Jones DC. Carcinomatous transformation of a sublingual dermoid cyst. A case report. Int J Oral Maxillofac Surg 2000;29(2):126127. DOI: 10.1016/S0901-5027(00)80009-0. 